International Journal of Electrical Engineering and Technology (IJEET)

Volume 11, Issue 4, June 2020, pp. 377-383, Article ID: IJEET_11_04_042

Available online at https://iaeme.com/Home/issue/IJEET? Volume $=11 \&$ Issue $=4$

ISSN Print: 0976-6545 and ISSN Online: 0976-6553

DOI: https://doi.org/10.34218/IJEET.11.4.2020.042

C) IAEME Publication

Scopus Indexed

\title{
IMPLEMENTATION OF A SMART FLASK USING INDUCTION HEATING AND ARDUINO MICROCONTROLLER
}

\author{
Jayakrishna Gupta \\ School of Electronics Engineering, Vellore Institute of Technology Vellore, India \\ Subhodeep Paul \\ School of Electronics Engineering, Vellore Institute of Technology, Vellore, India

\section{Dr. Budhaditya Bhattacharyya} \\ School of Electronics Engineering, Vellore Institute of Technology, Vellore, India
}

\begin{abstract}
With the continuous increase in connectivity for travel and the stable decrease in travel costs, the world starts to become a smaller place. With less travel time, a greater weightage is given to the individual mobility of a person. The ability for them to be on the move in a jiffy or continuously. Being on the go also means to stay comfortable while travelling. People consume hot and cold liquids when they travel. Having heated liquids on the go comes with the drawback of it cooling down before you have consumed it and vice versa for cold liquids. We have generated an idea to heat and maintain the liquid temperature without the help of an external power source. We achieve this goal with the help of induction heating, controlled by an Arduino to detect the temperature of the liquid. Further, we have enhanced our idea by adding a user input to set the required temperature of the liquid, this enables for liquids of various types to be used and kept at different temperatures.
\end{abstract}

Key words: Temperature Sensor, Induction Heating, Self-Heating.

Cite this Article: Jayakrishna Gupta, Subhodeep Paul and Dr. Budhaditya Bhattacharyya, Implementation of a Smart Flask using Induction Heating and Arduino Microcontroller. International Journal of Electrical Engineering and Technology, 11(4), 2020, pp. 377-383.

https://iaeme.com/Home/issue/IJEET?Volume $=11 \&$ Issue $=4$

\section{INTRODUCTION}

Heating technology has made a long journey from firewood to electric heating using conduction and now the latest and most efficient manner of induction heating [1]. 
But with fast moving time, comes the need to improve and devise new technologies. Today, in order to consume a hot liquid, we either have to carry it in a thermos, buy a hot liquid fresh or have access to a heating source.

The drawbacks with the above solutions are:

A thermos can hold liquids hot for a very limited time, after which the liquid losses its heat and obtains room temperature.

Buying a hot liquid fresh is not always a practical idea given the fact the increase in cost, availability of establishments to buy the hot liquid and availability of the hot liquid itself.

Having access to a heating source, is not always possible and therefore cannot be relied upon for a permanent solution.

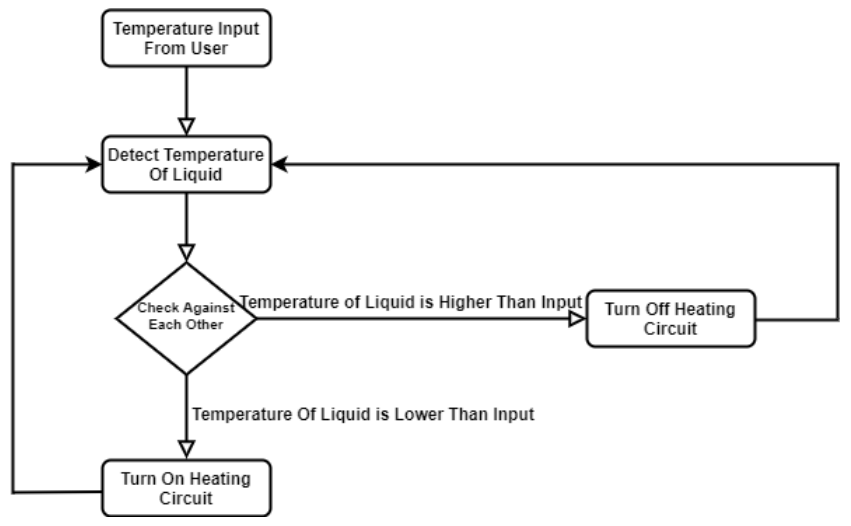

Figure 1 Visualization of Block Diagram

Even if the above statements are overlooked, the one major factor that is still effected is time. In the fast moving world we live in, time becomes an indispensable resource.

In this paper we have proposed an idea to further help advance induction heating by designing and perfecting an induction heating circuit that uses minute battery power as compared to the conventional mains power supply [2]. The basic working of the circuit is explained using the block diagram in Fig 1.

\section{SYSTEM ARCHITECTURE}

\section{Hardware}

\section{Arduino Uno}

Arduino UNO is a micro-controller board based on the AT-mega328P. It has 14 digital input/output pins, 6 analog inputs, a $16 \mathrm{MHz}$ ceramic resonator, a USB connection, a power jack, an ICSP header, and a reset button. The arduino board contains all the components needed to run the microcontroller. It can be connected using a USB to power it on. The pin configuration of Arduino UNO is given in fig 2. We have used Arduino UNO to power the LCD display, take input from the user and to control the heating circuit [3].

\section{LCD Display}

This is a basic 16 character by 2 line alphanumeric display. Black text on Green background. Utilizes the extremely common HD44780 parallel interface chipset. Interface code is freely available. You will need Minimum 6 general I/O pins to interface to this LCD screen. Includes LED backlight. Works in 4bit and 8 bit Mode. The pin diagram of the LCD display is shown in fig 3. In our project we have used the LCD display to show the temperature read by the DS18B20 temperature sensor as well as the temperature input given by the user. 


\section{DS18B20 Temperature Sensor}

The DS18B20 is a 1-wire programmable Temperature sensor from maxim integrated. It is widely used to measure temperature in hard environments like in chemical solutions, mines or soil etc. The constriction of the sensor is rugged and also can be purchased with a waterproof option making the mounting process easy. It can measure a wide range of temperature from $55^{\circ} \mathrm{C}$ to $+125^{\circ}$ with a decent accuracy of $\pm 5^{\circ} \mathrm{C}$. Each sensor has a unique address and requires only one pin of the MCU to transfer data so it a very good choice for measuring temperature at multiple points without compromising much of your digital pins on the micro-controller. The sensor has a query time of less than $750 \mathrm{~ms}$ and can be operated using a $3.0 \mathrm{~V}$ to $5.5 \mathrm{~V}$ power/data. In our project we have used this sensor to continuously monitor the temperature of the liquid inside the Smart flask.

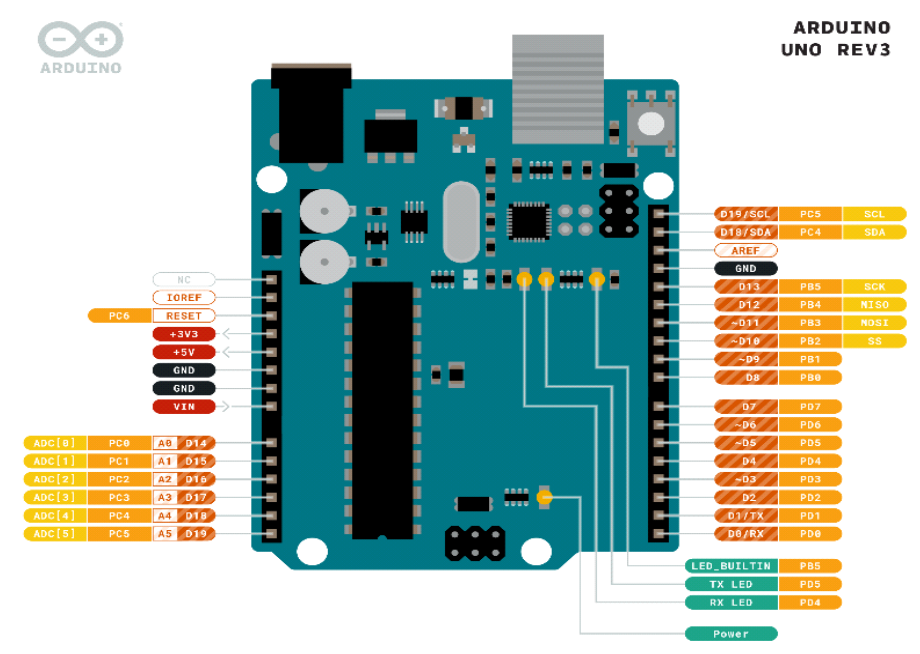

Figure 2 Visualization of Arduino UNO Pins

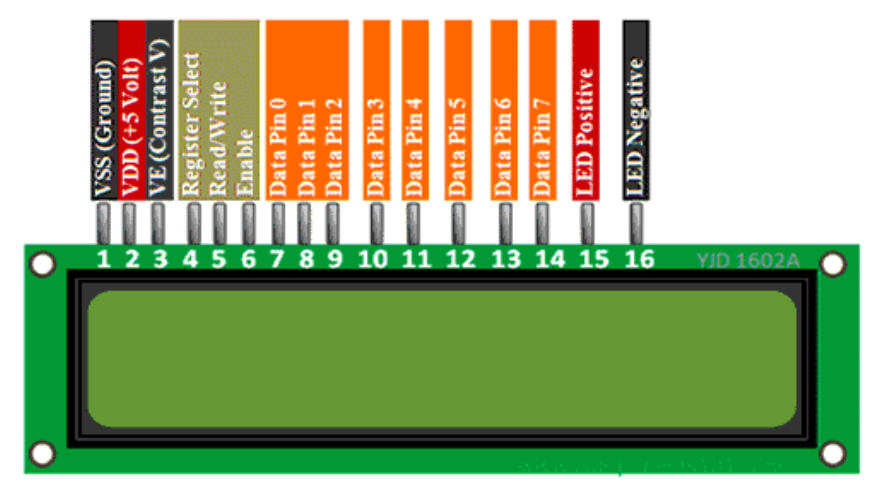

Figure 3 Visualization of LCD Display Pins

\section{IRFZ44N N Channel Power MOSFET}

The IRFZ44N is a N-channel MOSFET with a high drain current of 49A and low Rds value of $17.5 \mathrm{~mW}$. It also has a low threshold voltage of $4 \mathrm{~V}$ at which the MOSFET will start conducting. Hence it is commonly used with micro-controllers to drive with $5 \mathrm{~V}$. Two such MOSFETs are used in our project in the inverter circuit which switches alternately and coverts the input DC power to AC power. 


\section{BD139 Transistor}

It is a Medium Power NPN Transistor with a collector current of $1.5 \mathrm{~A}$ this transistor can be used to control (On/Off) bigger loads that consume less than 1.5A. In our project we have used this transistor to control the relay switch that controls the heating circuit.

\section{Goodsky rw-sh-112d Relay}

This relay is an electric circuit which controls the heating circuit based on the readings of the temperature circuit by opening and closing contacts in these circuits.

\section{Resonating LC circuit}

We have used an inductor and capacitor to make Resonating tank circuit to oscillate the circuit at its resonant frequency.

\section{Potentiometer}

We have used a potentiometer to control the brightness of the LCD display.

\section{$L E D$}

The led has been used to indicate the switching on and off of the heating circuit, additionally it has also been used the switch being pressed by the user.

\section{Software}

Arduino UNO uses the firmware Atmega8U2. The updates versions of the arduino UNO uses the Atmega16U2 version of the firmware. We program the arduino using arduino IDE. In order to run the arduino efficiently for our project, we needed to download additional libraries

\section{Libraries}

We had to download additional libraries in order to run the hardware from the arduino UNO. The following libraries were downloaded:

\section{Dallas Temperature Control Library}

This library is used with the DS18B20, a very small thermometer which is easily used with an arduino on any digital pin. This library is a refactor version of the original library, making it easier to use the thermometer. Making it easy and simple to use, with the limitation that, the look-up table may get complex for some associated function.

\section{One Wire Library}

The one wire network communicates with a slave device over a single data line, which also doubles up as to provide power to the slave devices. These libraries were designed to optimize the read and write capability to the slave devices.

\section{DESIGN AND CONSTRUCTIONS}

Our main circuit consists of an arduino, inverter/oscillator circuit, relay switching, LCD display, button inputs and heating coil. The basic connections are as follows.

- The Heating coil is connected to the inverter circuit.

- Inverter circuit is connected to 7V power supply.

- Relay is connected to the inverter circuit, power supply and arduino.

- Arduino is connected to LCD display, temperature sensor and button inputs sections 
The connections of the circuit are explained in Fig 4

\section{Circuit Diagram}

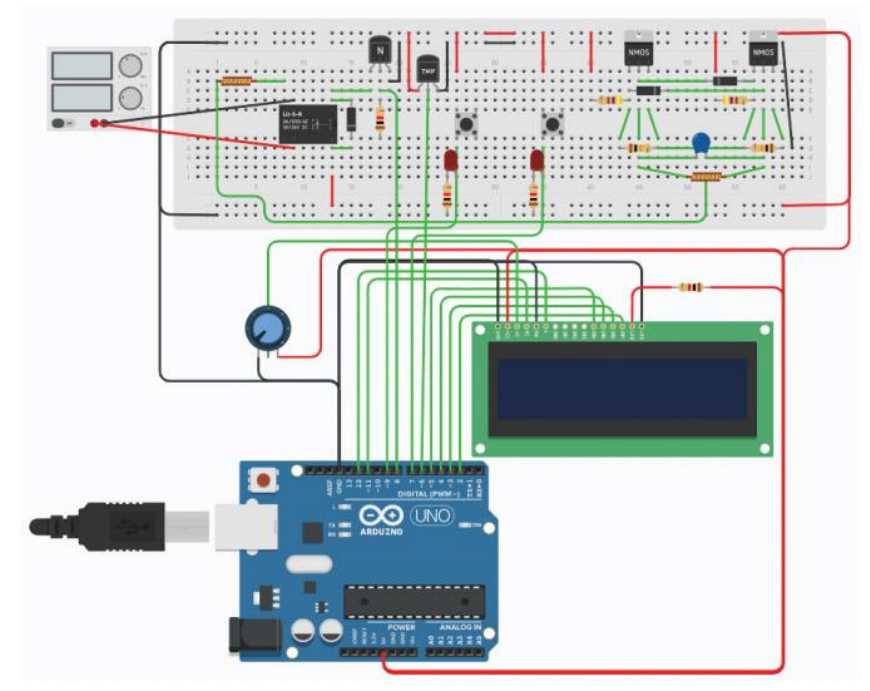

Figure 4 Visualization Of circuit connections

\section{Implementation}

The arduino UNO is provided power using a USB cable, giving a $5 \mathrm{~V}$ power supply. The heating circuit is given a 7V 1A power supply. Once the arduino is switched on. The first thing the arduino does is read the temperature of the liquid. The temperature of the liquid read is compared to the temperature input by the user. The temperature input of the user can be changed anytime during the operation of the circuit. Once the comparison of the temperature is carried out two operation of the circuit will take place.

\section{Input temperature is greater than the liquid temperature}

When the temperature of the liquid is less than the temperature input given by the user, the temperature of the liquid will have to be brought up to the input by the user. The arduino sends a signal to a transistor that is connected to the relay. The transistor switches the relay, this activates the heating circuit. The heating circuit is left on for the duration it takes to bring up the temperature of the liquid to the input by the user. During this time the temperature of the liquid is checked constantly against the user input with the help of the arduino.

\section{Input temperature is less than the liquid temperature}

When the temperature of the liquid is more than the temperature input given by the user, the liquid is left idle, so that by heat loss, the temperature of the liquid drops to the input given by the user. Therefore, the relay is left in its default position with the heating circuit turned off.

The arduino in the background, displays the current temperature of the liquid and the user input, giving the user a feedback on the working of the circuit. The constant switching of the arduino between the two modes, leads to the liquid being constant at the temperature input given by the user. 


\section{RESULTS}

The proposed technology was implemented successfully and the results obtained were highly satisfactory. The time taken to heat water and vegetable oil of different quantities for a $5^{\circ} \mathrm{C}$ change and a $10^{\circ} \mathrm{C}$ change has been tabulated and plotted. Table 1 shows the tabulated results for a change of $5^{\circ} \mathrm{C}$ of water. Table 2 shows the tabulated results for a change of $10^{\circ} \mathrm{C}$ of water. Table 3 shows the tabulated results for a change of $5^{\circ} \mathrm{C}$ of vegetable oil. Table 4 shows the tabulated results for a change of $10^{\circ} \mathrm{C}$ of vegetable oil. The results are as follows.

Table 1 Result of $5^{\circ} \mathrm{C}$ change of water

\begin{tabular}{cccc}
\hline $\begin{array}{c}\text { Quantity } \\
\text { (millilitres) }\end{array}$ & $\begin{array}{c}\text { Time Taken for 5 } \\
\text { Enegree rise } \\
\text { deconds) }\end{array}$ & $\begin{array}{c}\text { Energy Neded } \\
\text { (Jules) }\end{array}$ & $\begin{array}{c}\text { Energy } \\
\text { Consumed } \\
\text { (Jules) }\end{array}$ \\
\hline 30 & 216 & 628 & 1512 \\
\hline 35 & 228 & 735 & 1596 \\
40 & 240 & 840 & 1680 \\
\hline 45 & 265 & 945 & 1855 \\
\hline 50 & 287 & 1050 & 2009 \\
\hline
\end{tabular}

Table 2 Result for $10^{\circ} \mathrm{C}$ change of water

\begin{tabular}{cccc}
\hline $\begin{array}{c}\text { Quantity } \\
\text { (millilitres) }\end{array}$ & $\begin{array}{c}\text { Time Taken for } \\
\text { 10 degree rise } \\
\text { (seconds) }\end{array}$ & $\begin{array}{c}\text { Energy Needed } \\
\text { (Jules) }\end{array}$ & $\begin{array}{c}\text { Energy } \\
\text { Consumed } \\
\text { (Jules) }\end{array}$ \\
\hline 30 & 410 & 1260 & 2870 \\
\hline 35 & 422 & 1470 & 2954 \\
\hline 40 & 460 & 1680 & 3220 \\
\hline 45 & 501 & 1890 & 3507 \\
\hline 50 & 535 & 2100 & 3745 \\
\hline
\end{tabular}

Table 3 Result for $5^{\circ} \mathrm{C}$ change of vegetable oil

\begin{tabular}{cccc}
\hline $\begin{array}{c}\text { Quantity } \\
\text { (millilitres) }\end{array}$ & $\begin{array}{c}\text { Time Taken for 5 } \\
\text { degree rise } \\
\text { (seconds) }\end{array}$ & $\begin{array}{c}\text { Energy Needed } \\
\text { (Jules) }\end{array}$ & $\begin{array}{c}\text { Energy } \\
\text { Consumed } \\
\text { (Jules) }\end{array}$ \\
\hline 30 & 110 & 250.5 & 770 \\
\hline 35 & 126 & 292.3 & 882 \\
\hline 40 & 141 & 334 & 987 \\
\hline 45 & 161 & 375.8 & 1127 \\
\hline 50 & 187 & 417.5 & 1309 \\
\hline
\end{tabular}

Table 4 Result for $10^{\circ} \mathrm{C}$ change of vegetable oil

\begin{tabular}{cccc}
\hline $\begin{array}{c}\text { Quantity } \\
\text { (millilitres) }\end{array}$ & $\begin{array}{c}\text { Time Taken for } \\
\text { 10 degree rise } \\
\text { (seconds) }\end{array}$ & $\begin{array}{c}\text { Energy Needed } \\
\text { (Jules) }\end{array}$ & $\begin{array}{c}\text { Energy } \\
\text { Consumed } \\
\text { (Jules) }\end{array}$ \\
\hline 30 & 216 & 501 & 1512 \\
\hline 35 & 230 & 584.5 & 1610 \\
\hline 40 & 246 & 668 & 1722 \\
\hline 45 & 277 & 751.5 & 1939 \\
\hline 50 & 300 & 835 & 2100 \\
\hline
\end{tabular}




\section{CONCLUSION}

In this paper induction heating of liquid with a rechargeable battery source was implemented. Beginning with the description of the complete system hardware and software used and further on explaining the working of the model.

The proposed system fulfilled the requirements and displayed the results. In this process we also achieved our goal in a cheap and effective manner.

Introduction of induction heating using a very small power source have improved the current technological enhancements in this field. For further enhancement, the user input can be taken from a mobile device, connected over Wi-Fi to the smart flask [4][5][6][7][8].

\section{REFERENCES}

[1] Ahmed H. E. Sherwali, William G. Dunford. (2019) "Experimental evaluation of heating water by electromagnetic induction". IEEE Canadian Conference of Electrical and Computer Engineering (CCECE).

[2] Yeliz Tezcan, Mutlu Boztepe. (2018) "Independent power control in dual coil induction heating system for liquid foods". 978-1-5386-2353-4/18/.

[3] Leo Louis. (2016) "Working principle of arduino and using it as a tool for study and research. International Journal of Control, Automation, Communication and Systems (IJCACS), Vol.1, No.2.

[4] Tomasz Osuch, Tomasz Jurek, Konrad Markowski, (2016) Student Member, IEEE, and Kazimierz Jedrzejewski. "Simultaneous measurement of liquid level and temperature using tilted fiber Bragg grating". IEEE Sensors Journal, Vol. 16, No. 5, March 1.

[5] Dr.P.B.Pankajavalli, Mr.R.Saikumar, Mr.R.Maheswaran. (2017) "Hydration reminding smart bottle: IoT experimentation". International Conference on Innovations in Power and Advanced Computing Technologies [i-PACT2017]

[6] Qian Zhao, Kai Xu. "Measurement of liquid level with a small surface area using highfrequency electromagnetic sensing technique". 978-1-4799-6144-6/15/

[7] Y. Sonia Soubam, Manisha Agrawal, Vinayak Naik. (2017) "Using an Arduino and a smart watch to measure liquid consumed from any container". 2017 9th International Conference on Communication Systems and Networks (COMSNETS)

[8] Bo Dong IEEE Student Member, Ryan Gallant IEEE Student Member, and Subir Biswas IEEE Senior Member. (2014) "A self-monitoring water bottle for tracking liquid intake". 2014 Health Innovations and Point-of-Care Technologies Conference Seattle, Washington USA, October 8-10

[9] K. Anusha, L. Baala Gajakreedan, S. Nishanth Kumar and S. Vignesh Rajarathinam, (2017) Persistence of Vision using Arduino. International Journal of Electronics and Communication Engineering and Technology, 8(4), pp. 7-12

[10] Sayyed Viquar Ahmed, (2020) Smart Glasses using Arduino, International Journal of Computer Engineering and Technology, 11(1), pp.18-22.

[11] Sridevi, (2018) Smart Wireless Sensor Network for Agricultural Environment Using Arduino UNO. International Journal of Electronics and Communication Engineering and Technology, 9(4), pp.10-21

[12] Ritam Sahu, Moyuri Shil, Rimpi Datta, Piyu Sarcar, (2019) Street Light Glows on Detecting the Vehicle Movement Using Arduino Uno, International Journal of Electrical Engineering \& Technology, 10(3), pp. 16-20 